\title{
The Relationship between Predicting Personality Using Physiognomy and Through Using Personality Scale
}

\author{
Mohammad L. Abulaban ${ }^{1}$, Sahar S. Muzher ${ }^{2} \&$ Ahmad M. Thawabieh ${ }^{3, *}$ \\ ${ }^{1}$ Director and Coach of Physiognomy (Alfarasa Center), Jordan \\ ${ }^{2}$ Psychologist and Trainer for Life Skills, Jordan \\ ${ }^{3}$ Department of Educational Psychology, Faculty of Educational Sciences, Tafila Technical University, Jordan \\ *Correspondence: Department of Educational Psychology, Faculty of Educational Sciences, Tafila Technical \\ University, Jordan. Tel: 962-777-758-156. E-mail: ahmadthawabieh@yahoo.com
}

Received: May 11, 2018

doi:10.5430/wjss.v5n2p22
Accepted: May 28, 2018 Online Published: June 22, 2018

URL: https://doi.org/10.5430/wjss.v5n2p22

\begin{abstract}
This study aims at investigating the relationship between predicting personality types through physiognomy on the one hand and through using personality scale on the other. 474 volunteers participated. 3 scales were used to collect data: physiognomy judgments, Abulaban physiognomy scale and Herman brain dominance scale. The results indicated that there were high positive correlations between the three scales. The study recommends using physiognomy as a method to determine personality type as it is easy, valid, and provides fast results.
\end{abstract}

Keywords: personality, body features, physiognomy, HBDI

\section{Introduction}

Physiognomy originated from the early beginning of the human life on earth. The accumulation of human experiences over the years through observation and experiment led to a remarkable development in this science, until it reached advanced stages.

The idea of linking the features of a person with his/her personality has its roots in ancient civilizations. The ancient Chinese (two thousand and seven hundred years ago), were one of the first nations to study and identify the principles of Physiognomy. They named it (Mian Chiang), which means knowledge of the features - i.e. reading the faces. They read faces through human biological expressions to diagnose diseases, to know the type of personality and to predict the future of the individual.

Physiognomy was also known to the ancient Egyptian civilization. Some writings on the subject were discovered on papyrus.

One of the first nations to scientifically study Physiognomy was the Greeks. It appeared in their literature and poetry. Notably, the philosopher Aristotle, in his addendum to History of Animals discussed how to read a person's character from their face. He also wrote a study devoted entirely to face reading. The mathematician Pythagoras's, Hippocrates focused on the effect of climates and geographical environment of the regions on the personalities of the individuals. He developed a theory in physiognomy which states that the human body has four types of fluids which determine the personality and the characteristics of the individual.

Arabs also had their experience in physiognomy. They related the body features to hidden characteristics of the human being. That the practice of physiognomy or 'Firasa' was known to the Arabs is evident in several references within the Quran which show the general acceptance of the idea that the outer form of the body reveals the inner state of the person. There is also a legal precedent for the use of physiognomy within Islam. The Quran also records that physiognomy is a useful tool in the settlement of paternity and genealogical disputes. Given the relation between chiromancy and physiognomy it would be surprising if ancient Arabic culture knew nothing of the significance of the hands, particularly since there is so much evidence to point that the European interest in hand reading, which began in the twelfth century, had its origins in Arab culture. (http://www.johnnyfincham.com/history/arabic.htm). 
Physiognomy was presented as a particularly useful skill for the Ottoman court due to its ability to evaluate inner moral character with scientific precision. Based on such knowledge, a prejudgment could be passed with an instrumental coating of impartiality. Moreover, men with prized moral qualities could be selected for the ruling elite. The science also offered the Sultan and his court a modus operandi for attaining self-knowledge and, if combined with moral self-disciplining (riyāḍat), a way to acquire divine characteristics, Lelić (2017). Ibn Sina, Elshafi and Ibn El-Arabi also did research and added a lot to the science of physiognomy. The most famous book of physiognomy is Politics in Physiognomy, which was written by Abi Shams Eddin Mohammed Bin Talib Al-Ansari, where he stated the provisions of physiognomy with some detail. (Mar, 1974). Also they related body characteristics kinship with other relatives.

The first great advancement of physiognomy in the West came in 1775 with the publication of Essays on Physiognomy by Johann Kasper Lavater (1741-1801), (the father of physiognomy), a pastor and poet in Zurich. His book, with its scores of superb illustrations and his rigorous effort to produce a classification system, was the first Western attempt to approach physiognomy as a scientific study. Many followed in Lavater's footsteps, for example, Mary Olmsted Stanton. She wrote: The Encyclopedia of Face and Form Reading (Mac Fulfer). Physiognomy grew throughout the 18th century and into the 19th century, and it was discussed by academics, such as; Balzac, Joseph Ducreux, Charles Dickens, Thomas Hardy, Charlotte Brontë, Thomas Browne, Amelia Opie, and George Borrow.

\section{What is Physiognomy?}

Physiognomy is a Greek term composed of two parts: physis which means: nature and 'gnomon' which means judge the body appearance (Benjamin, 2007). Wikipedia definition is: "the assessment of character or personality from a person's outer appearance, especially the face". (https://wikipedia.org/wiki/Physiognomy).

Hadib (1998) defined it as "the science that studies the sections and the general shape of the body, face or palm". The Merriam Webster dictionary definition is:"the art of discovering temperament and character from outward appearance" and "the facial features held to show qualities of mind or character by their configuration or expression". While the Oxford Dictionary definition is: "The supposed art of judging character from facial characteristics. The British Encyclopedia (Encyclopedia Britannica) defined it as: "the study of the systematic correspondence of psychological characteristics to facial features or body structure. Jalal (2011) defined it as "the inference of the inner morality of a person through their environment, or the inference of ethics, virtues or vices through the study of the human body, form, colors and words. Bahij (2010) defined it as a science that searches the external features of people to reveal their inner qualities. Human physiognomy is the science that is involved with deducing the internal human characteristics by studying and analyzing the external appearance, such as the face, the body, etc. (Parsons, 1747).

\section{Body Features \& Physiognomy}

\subsection{Body Type}

Ernst Kretschmer classified the human body into 3 types:

1- Asthenic Type (thin, small, lame, long arms and legs, small head, triangular face):

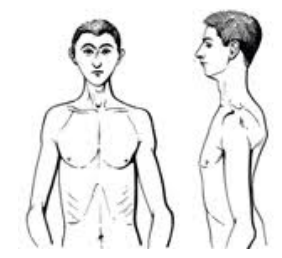

Figure 1. Asthenic Type

Persons with this type of character are easily affected; they always help others, sensitive and emotional. They tend to age quickly.

2- Pyknic Type (breast, head, stomach, medium height, a soft broad face on a short massive neck) 


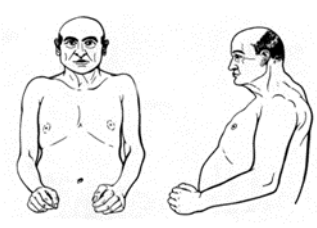

Figure 2. Pyknic Type

Persons with this body type are: born to manage and/or lead and master people, ideal manager and/or leader. They are intelligent and sensitive. They avoid making eye contact with people. Pyknic type are sociable and they love food.

3- Athletic Type (Strong muscles and bones, tall, stiff, wide and triangular body, oval or angular (square) face, flat nose, long neck).

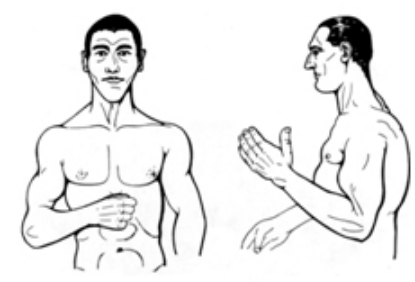

Figure 3. Athletic Type

Persons with this type of body are: able to manage (not as well as pyknic type) or be managed (less than asthenic type). Their management is physical, through body and senses. Athletic types usually have angular (square) hands and/or fingers. Athletic types are usually active, social, reckless and aggressive. (http://facereadingdictionary.com/relationship-between-body-types-and-character/face-reading-physiognomy-meanin $\mathrm{g} /$ )

Face Types

The source of the figure and information from (https://socialmettle.com/face-reading-techniques)

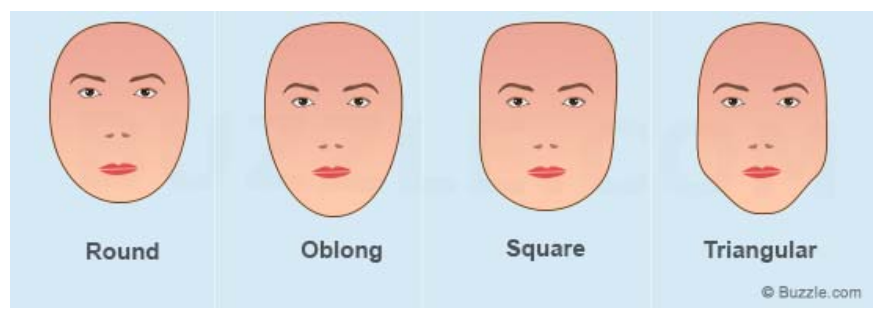

Figure 4. Face Shapes

1- Round type: Emotional individuals, sensitive, caring, have strong sexual fantasies, usually build stable relationships.

2- Oblong type: These people may have a muscular or athletic physique. They are thought to be practical, methodical and tend to be a tad more overworked. They may have problematic relationships.

3- Square type: These people are thought to have an intelligent, analytical and decisive mind. The face shape is associated with an aggressive and dominating nature.

4- Triangular type: These face types are usually related to a thin body and intellectual and moral suasion. They are considered to be creative and thought to have a fiery temperament according to the Chinese face readers. 
Other parts of the body, such as; lips, hair, forehead, eyes, eyebrows, hand, fingers, ears .... etc, were used to predict the personality characters.

Personality is a specific combination of emotion models, response patterns, and individual behavior. Different theorists present their own definitions based on their theoretical views (Angler, 2009). Jeel (2000) defined personality as the group of aptitudes, interests acquired from experience and inherited biological motives. According to Allport, personality is the dynamic organization of psychological, physical, mental and social systems which determine the individual behavior. (Majeed, 2008). Abdulkhaliq (1996), states that personality is a fixed and highly durable complex behavioral pattern, which distinguishes the individual from other people. It consists of a unique organization of functions and traits, and it includes mental capacity, emotions, body composition and physiological functions. These complex structures determine the individual's method of response, and his/her unique approach to adapt to the environment. Cattell defined personality as the prediction of the behavior when the person is placed in certain circumstances (Mustafa, 2011). According to Eysenck, it is the total number of behavioral patterns and underlying phenomenon, caused by genetics and the environment. (Gubari \& Abu shaiera, 2010). It could be argued that personality refers to the external characteristics, which make us differ from others, as a result of our individual differences (Salhi, 2013). Isawi (2002) indicated that the personality is the combination of individual personal traits, growth, interests, and thoughts, which result from the interaction between heredity and the environment. In addition to that, some personal traits are formed as a result of environmental, political, religions and intellectual methods of socialization.

\subsection{Related Literature}

Many studies have been conducted to explore the personality traits and their relationship with body features; Gavrilescu, and Vizireanu, N. (2017), proposed a novel three-layered neural network-based structure for predicting the Sixteen Personality Factors from facial features analyzed using Facial Action Coding System (FACS). The proposed structure is built on three layers: a base layer where the facial features are extracted from each video frame using a multi-state face model and the intensity levels of 27 Action Units (AUs) are computed. An intermediary level where an AU activity map is built containing all AUs' intensity levels extracted from the base layer in a frame-by-frame manner. A top layer consisting of 16 feed-forward neural networks trained via back propagation which analyze the patterns in the AU activity map and compute scores from 1 to 10 , predicting each of the 16 personality traits. The results showed that the proposed structure predicts warmth, emotional stability, liveliness, social boldness, sensitivity, vigilance, and tension with an accuracy of over $80 \%$. There was a significant relationship between the emotions elicited from the analyzed subjects the prediction based on each of the 16 personality traits showing high prediction accuracy. In addition, there was a notable correlation between distinct sets of AUs present at high-intensity levels and increased personality trait prediction accuracy. The system converges to a stable result in no more than 1 min, making it faster and more practical than the Sixteen Personality Factors Questionnaire and suitable for real-time monitoring of people's personality traits.

Zhang, Qin, Lei Dong, Gao, Xu, Hu (2017) evaluated the relationship between individuals' personality traits and intelligence from their face features. To assess the possible correlations between personality traits and face images, they first construct a dataset consisting of face photographs, personality criteria, and intelligence criteria. Then, they build an end-to-end convolutional neural network for prediction of personality traits and intelligence to investigate whether self-reported personality traits and intelligence can be predicted reliably from a face image. The results showed the following: rule-consciousness and tension can be reliably predicted from face images, and it is difficult, if not impossible, to predict intelligence from face images.

Awaja (2017) built an accurate semantically enriched system, through ontology, for the deduction of personality in modern physiognomy domain. A knowledge base is created, that includes the (HPDPOnto) ontology, set of individuals, and set of SWRL rule through building the semantic system. The accuracy of the approach including the physiognomy ontology is evaluated through measuring the correctness of the personality deduction results. The proposed system is evaluated using cases provided by a physiognomy expert. The results have shown that the system has correctly deduced 19 out of 21 cases with ratio correctness of $90 \%$.

Shu, Zhang, Tang, Xie, and Yan (2016) propose an intelligent system for reading frontal faces to extract human personality in the face reader framework which defines 19 facial attributes, then collect a Chinese face database containing 5,562 face photos. After that they construct a data base which stores links between facial attributes and a collection of 200 face images of Chinese famous persons. To estimate the facial attributes, they train an intelligent machine- learning model on the annotated data set. This search depends on FRP-net structure to estimate the facial attributes, and several multi layers, which is trained on the collected Chinese face database. This research presents an 
intelligent way to recognize the personality from faces using the 23 physiognomy. However it depends on and uses Chinese physiognomy only. It does not support other cultures or physiognomy.

The study of Sutin and Terracciano (2016) aimed to replicate the associations between weight discrimination and obesity status in a young adult sample, to examine whether sex, race, or ethnicity affect these associations, and test whether personality is associated with the subjective experience of body weight and discrepancies between perceived and actual weight. Participants $(n=15,669)$ from wave 4 of the national longitudinal study of adolescent health completed a five-factor model personality measure and reported their weight, height, and perception of weight category (e.g., overweight). Trained staff measured participants' height, weight, and waist circumference. Conscientiousness was associated with healthier weight, with a nearly $5 \mathrm{~kg}$ difference between the top and bottom quartiles. Neuroticism among women and extroversion among men were associated with higher adiposity. Neuroticism was also associated with misperceived heavier weight, whereas extroversion was associated with misperceived taller and leaner shape. The associations were similar across race/ethnic groups. Personality is associated with objective and subjective adiposity in young adulthood.

Caulfield, Ewing, Bank and Rhodes (2016, p. 503) "investigated the developmental trajectory of explicit trust judgments from faces, and the contribution made by emotion cues across age groups. 5-, 7-, 10-year-olds, and adults rated the trustworthiness of trustworthy and untrustworthy faces with neutral expressions. The same participants also rated faces displaying overt happy and angry expressions, allowing us to investigate whether emotion cues modulate trustworthiness judgments similarly in children and adults. Results showed that the ability to evaluate the trustworthiness of faces starts with childhood but may not be adult like until 10 years of age. Moreover, emotion cues modulate trust judgments in young children, as well as adults. Anger cues diminished the appearance of trustworthiness for participants from 5 years of age and happy cues increased it, although this effect did not consistently emerge until later in childhood, that is, 10 years of age. These associations also extended to more subtle emotion cues present in neutral faces. Results indicated also that young children are sensitive to facial trustworthiness and suggest that similar expression cues modulate these judgments in children and adults."

The study of Kini and Kumar (2014) aimed to detect the relationship between measurements of the facial features and judging the character of a person based on the person's facial features. It is said that facial features like face shape, ear length, forehead length and forehead width, eye distance or the entire body features are related to a person's thinking pattern. This relation is made use of to identify the personality of an individual. The experimentation so far has been conducted on several people and the results obtained from the implementation of the paper match with the characters of the people involved in the experimentation. This method is a cost effective, time saving and highly time efficient technique that involves personality identification by measuring the facial features.

Hassin and Trope (2000) examined several aspects and consequences of the process of reading personality traits from faces. They used faces with neutral expressions; they also demonstrated that personality information conveyed in the faces changes the interpretation of verbal information. The results showed that physiognomic information had a consistent effect on decisions and creates assurance of judgments.

\subsection{Statement of the Problem}

Determination of a person's personality type is considered a most important issue, because this knowledge will help everyone understand themselves and others. Therefore, this study aimed to validate 2 personality scales. The first one depends upon physiognomy, while the other depends upon different body features and some behavioral aspects. To be precise, this study aimed to answer the following questions:

1. What are the distributions of personality types among the sample of the study?

2. What is the relationship between Physiognomy scale and HBDI?

3. What is the relationship between Abulaban Physiognomy Scale (APS) scale and HBDI?

4. What is the relationship between Physiognomy scale and APS?

\subsection{The Importance of the Study}

This study aims to provide an easy scale to identify the personality type in order to save time, money and effort; through using the body characteristics and physiognomy. It also aims to validate Abulaban personality scale using concurrent validity. 


\section{Method}

\subsection{Design}

The study adopted the descriptive analytical correctional design because it fits the objectives of the study.

\subsection{Sample}

The sample of the study consisted of 474 volunteers from both sexes (195 male, 279 female) distributed all over Jordan. Table (1) represents the sample distribution.

Table 1. Study Sample

\begin{tabular}{cccccccc}
\hline \multicolumn{7}{c}{ Geographical distribution } & \\
\cline { 1 - 6 } sex & Male & 26 & 29 & 7 & 14 & 119 & 195 \\
& Female & 20 & 55 & 33 & 27 & 144 & 279 \\
\multicolumn{2}{c}{ Total } & 46 & 84 & 40 & 41 & 263 & 474 \\
\hline
\end{tabular}

\subsection{Instruments}

The researchers used 3 scales to collect data: physiognomy, Abulaban scale, and Herman personality scale.

4.3.1 Physiognomy Prediction: according to the judgement of experts in physiognomy, the type of the personality will be determined through colors.

4.3.2 Abulaban Physiognomy Scale (APS): This scale was developed by the Mohammad Abulaban depending on his experience in physiognomy. It consisted of 2 parts: (A) 10 items related to the body features: height, feet size, abdomen shape, nose shape, figure shape, eye size, lips, and legs length: abdomen length; B) 6 behavioral items were used to support the decision of determining the personality type that depends upon the body features and in order to determine the dominant personality color. The 4 main colors of personality were: Blue Personality. Individuals with this color were people who: are good at short-term planning, interested in accuracy, details and quantities. They are interested in numbers and calculations, practical, professional, walking in changing speed, have disruptive visual communication, and interact carefully with others. Green Personality: administrative, likes office work, long-term planners, look down during walking, little eye contact, likes healthy food (vegetables), broad, cold and formal social relations, calm, apathy and cold interaction with others. Red Personality: holistic and dynamic thinking, doesn't like details, quantities or numbers, likes jobs that need free locomotion and suitable to their principles, cannot stay at the same place, likes linguistic skills, high social relations, empathetic, high level of interaction and engaging in social relations. They like carbohydrates, and maintain a high, effective level of visual contact. Yellow Personality: imaginative thinking, doesn't like details, quantities or numbers, likes arts: singing, theaters, acting, has good social relations with all, likes different types of food: especially sea food and nuts, empathy interaction but for short period. (Appendix A).

As it is almost impossible for a person to be of a pure personality color, six more personality colors were added by mixing the original basic colors: Turquoise, a mixture of green and blue. Purple, mixture of blue and red. Orange, a mixture of red and yellow. Olive, a mixture of green and yellow. Brown, a mixture of green and red. Gray, a mixture of blue and yellow.

It is also important to state that a character's behavior patterns are not entirely determined by the attributes of any personality color. The character pyramid figure bellow explains other significant factors that affect individuals, therefore rendering the colors as a mere description of the attributes of the character rather than a judgment of the individual. 


\section{Personality Pyramid:}

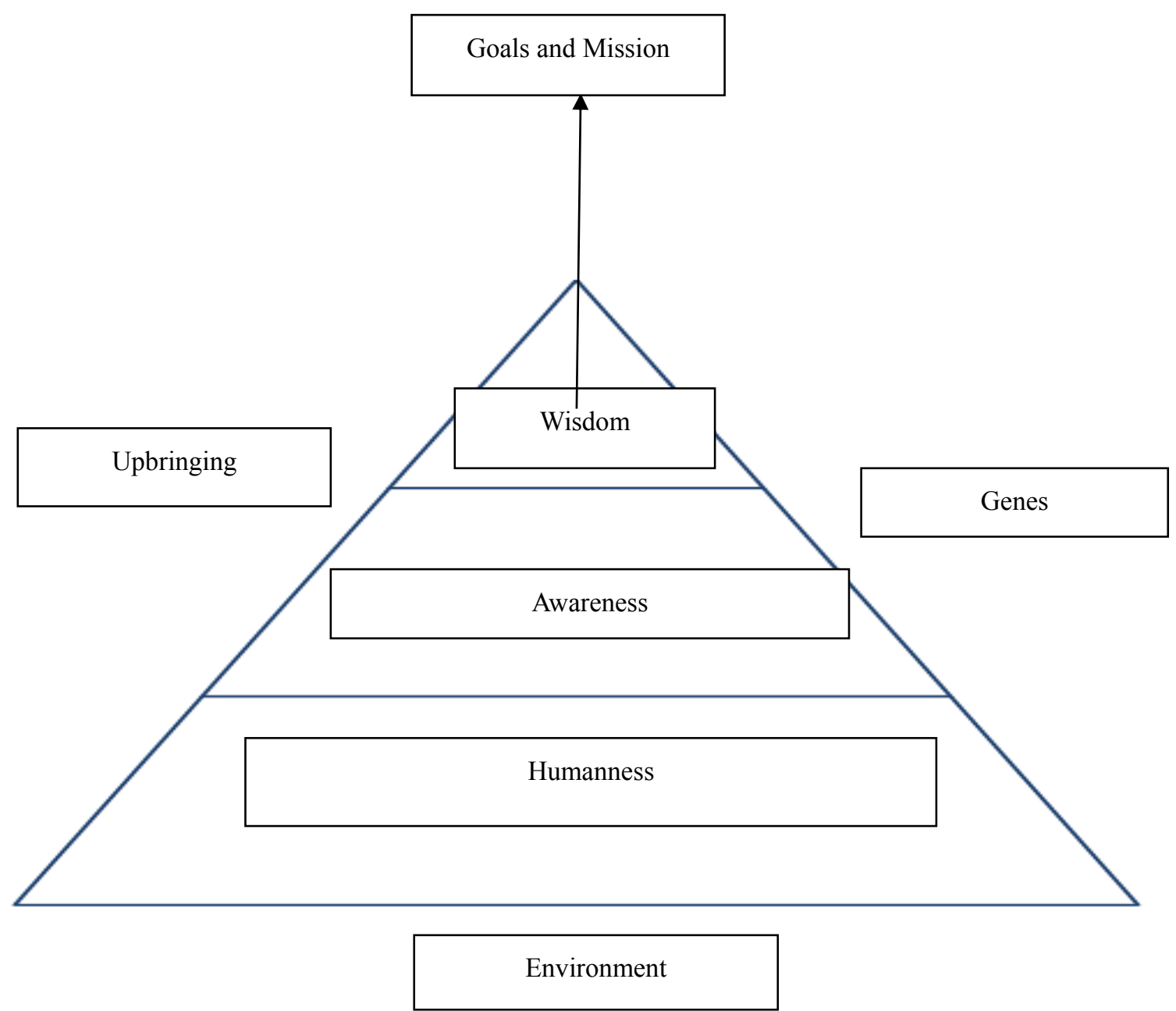

Figure 5. Personality Pyramid

The three tiers of the character pyramid (figure 5): humanness, awareness and wisdom are supported by the environment, genes and upbringing at all three angles. A dynamic pyramid can be drawn, to be altered according to different age groups or the circumstances that an individual is going through. All of the above collectively reflects on the behavior of individuals and the significance of the goals they devote themselves to - The goals are represented by an up shooting arrow from the top of the pyramid. This arrow is considered the fixed criterion to evaluate the size of the character pyramid.

The base tier, humanness, refers to the collective attributes and qualities considered positive by all humans such as integrity, loyalty, honesty etc. the central tier, awareness, refers to a person's ability to realize and understand their abilities, to believe in themselves and to comprehend their surroundings using their mental abilities. The third tire, wisdom, refers to having a person's words and actions in accord, delivered at the right time and place and to the right people.

The pyramid tiers alone are not enough to evaluate behavior, as other elements, such as the geographical and social environment, play a crucial role in forming and supporting the base of the pyramid.

Another factor, heredity (or genes) supports one angle of the pyramid, while the other angle is supported by upbringing, whether positive or otherwise.

\subsubsection{The Herrmann Brain Dominance Instrument (HBDI)}

Herman scale (HBDI) was used to validate the previous 2 scales; this scale was translated into Arabic language and adapted to the Jordanian environment by different researchers (Alhelat, 2015, and Nofal and Abu Awad, 2007 ). this 
scale classifies the personality styles into 4 categories (A, B, C, and D) each style is similar to one of the personality styles which was developed by physiognomy according to APS ( $\mathrm{A}=$ Green, $\mathrm{B}=\mathrm{Blue}, \mathrm{C}=$ Yellow, and $\mathrm{D}=\mathrm{Red})$.

\subsubsection{Validity}

Validity of the instruments was checked using expert judgments, 5 experts in physiognomy and psychology.

\subsubsection{Reliability}

Reliability of the study tools was checked using: test-retest; pilot sample consisted of 38 participants was used to check reliability, using test re-test method. The tools were applied 2 times; the duration time between the two applications was 10 days. Table (3) represents the findings for reliability concerning the two methods.

Table 2. Reliability of the Instruments

\begin{tabular}{lc}
\hline \multicolumn{1}{c}{ Scale } & Test re-test \\
\hline Physiognomy Prediction & 0.972 \\
APS & 0.988 \\
HBDI & 0.873 \\
\hline
\end{tabular}

Table 2 shows that the figures for reliability are appropriate for this study purposes.

\subsection{Procedures}

The researchers asked for permission from some institutions (universities and companies) to apply the study instruments. A group of physiognomists consisted of 6 persons were responsible for applying the study tools. Their job was first to determine the personality color type using their experience in determining the personality color through facial features; second to clarify any ambiguity regarding the items of the instruments. Respondents were asked to respond to the instruments using flyers. They were informed that responding to the instruments is not compulsory, although their commitment, accuracy and completion of all items will be reflected on the study results. It took about 25 minutes to complete responding to the tools.

\section{Results}

\subsection{Results of Question 1.}

For answering Q1 which states: " What are the distributions of personality types among the sample of the study?" Descriptive statistics were used; frequencies and percentages were calculated. Table 3 represents the findings.

Table 3. Frequencies and Percentages for Personality Colors Distribution

\begin{tabular}{lcccccc}
\hline & \multicolumn{2}{c}{ Physiognomy } & \multicolumn{2}{c}{ APS } & \multicolumn{2}{c}{ HBDI } \\
\hline $\begin{array}{l}\text { Color of } \\
\text { Personality Frequency }\end{array}$ & \multicolumn{2}{c}{ Percent } & Frequency & Percent & Frequency & Percentage \\
\hline Green (1) & 71 & 15.0 & 71 & 15.0 & 56 & 11.8 \\
Blue (2) & 196 & 41.4 & 196 & 41.4 & 185 & 39.0 \\
Yellow (3) & 158 & 33.3 & 158 & 33.3 & 184 & 38.8 \\
Red (4) & 49 & 10.3 & 49 & 10.3 & 49 & 10.3 \\
Total & 474 & 100.0 & 474 & 100.0 & 474 & 100.0 \\
\hline
\end{tabular}

Table 3 shows that the distributions of personalities were similar in physiognomy scale and APS, they were arranged designingly as follows: blue (41.4\%), yellow (33.3), green (15\%), and red (10\%). While; the distribution according to HBDI was different in ratio although it had similar order distribution, the colors were distributed as follows: blue $(39 \%)$, yellow (38.8\%), green $(11.8 \%)$, and red $(10.3 \%)$. 
Figures 1, 2, and 3 represent the distribution of personality colors among the 3 scales $(1=$ green, $2=$ blue, $3=$ yellow, $4=$ red).

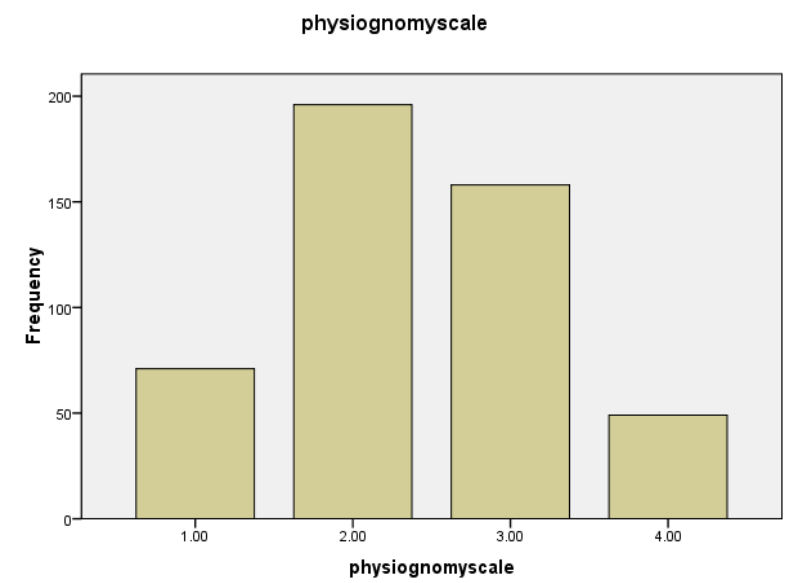

Figure 1. The Distribution of Personalities According to Physiognomy

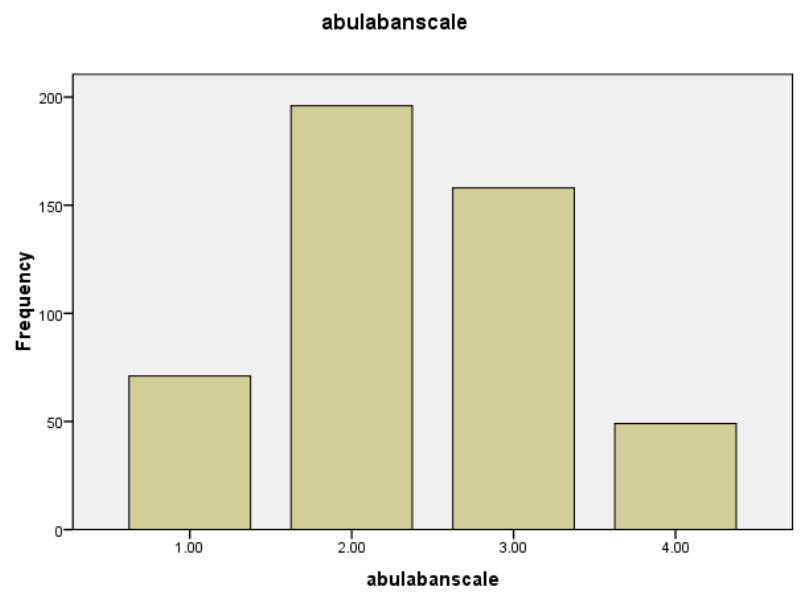

Figure 2. The Distribution of Personalities According to APS

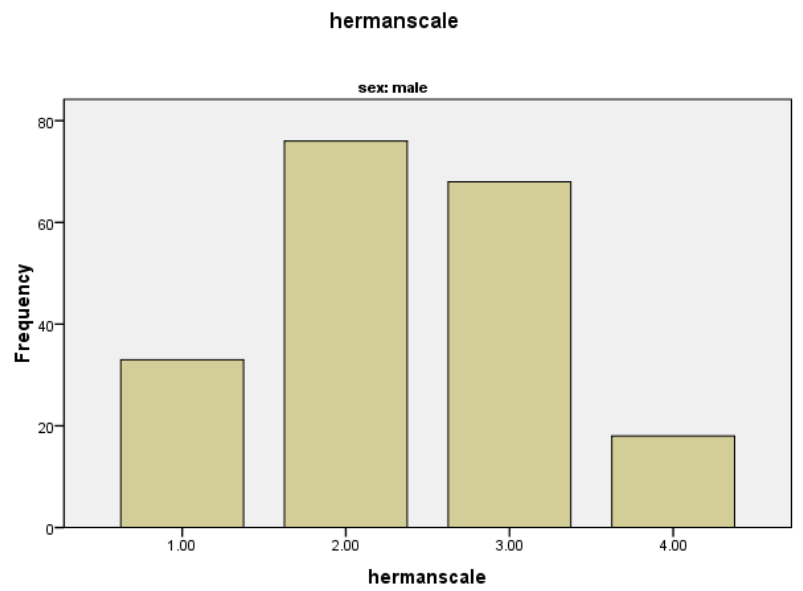

Figure 3. The Distribution of Personalities According to HBDI 
Table 4. Represents the distribution of personality types according to sex.

Table 4. Frequencies and Percentages for Personality Colors Distribution According to Sex

\begin{tabular}{cllllllc}
\hline \multirow{2}{*}{ Color of Personality Sex } & \multicolumn{3}{c}{$\begin{array}{c}\text { Physiognomy } \\
\text { Frequency Percent }\end{array}$} & $\begin{array}{c}\text { APS } \\
\text { Frequency Percent }\end{array}$ & \multicolumn{2}{c}{ HBDI } \\
Frequency Percent
\end{tabular}

As shown in table 4 the distribution of personality colors were similar for both sexes in physiognomy and APS scales. The distributions of colors were similar among the 3 scales for males and females; they were: blue, yellow, green and red; successively.

\subsection{Results of Question 2}

For answering Q2 which states:" What is the relationship between Physiognomy scale and HBDI?" Chi square $\left(\chi^{2}\right)$ goodness of fit test was used, table 5 indicates the cross tabulation between the physiognomy scale and HBDI.

Table 5. Physiognomy Scale * HBDI Cross Tabulation

\begin{tabular}{|c|c|c|c|c|c|c|}
\hline & \multirow[b]{2}{*}{ PERSONALITY } & \multicolumn{4}{|c|}{ HBDI } & \multirow[b]{2}{*}{ Total } \\
\hline & & 1 & 2 & 3 & 4 & \\
\hline \multirow[t]{4}{*}{ Physiognomy scale } & 1 & 49 & 9 & 13 & 0 & 71 \\
\hline & 2 & 3 & 169 & 19 & 5 & 196 \\
\hline & 3 & 3 & 2 & 149 & 4 & 158 \\
\hline & 4 & 1 & 5 & 3 & 40 & 49 \\
\hline Total & & 56 & 185 & 184 & 49 & 474 \\
\hline
\end{tabular}

Table 6. Represents Chi Square ( $\chi 2)$ test for goodness of fit between physiognomy scale and HBDI.

Table 6. Chi-Square Test for Goodness of Fit for Physiognomy and HBDI

\begin{tabular}{lccc}
\hline & Value & df & Sig \\
\hline Pearson Chi-Square & 8.823 & 9 & .000 \\
Likelihood Ratio & 688.003 & 9 & .000 \\
Linear-by-Linear Association & 288.555 & 1 & .000 \\
N of Valid Cases & 474 & & \\
\hline
\end{tabular}

Table 6 indicated that Pearson Chi-Square value $=8.823$ and this value is statistically significant $(\alpha=0.05)$. Table 7 represents Pearson's Correlation between the 2 scales, it equals 0.78 , and this value is statistically significant $(\alpha=$ $0.05)$. 
Table 7. Correlation between Physiognomy and HBDI

\begin{tabular}{lccccc}
\hline & & \multicolumn{1}{c}{$\begin{array}{c}\text { Asymp. Std. } \\
\text { Error }\end{array}$} & Approx. T & Approx. Sig. \\
\hline Interval by Interval & Pearson's R & .781 & .032 & 27.174 & .000 \\
Ordinal by Ordinal & Spearman Correlation & .782 & .031 & 27.228 & .000 \\
\hline
\end{tabular}

\subsection{Results of Question 3}

For answering Q3 which states:" What is the relationship between Abulaban Physiognomy Scale (APS) and HBDI?" Chi square $\left(\chi^{2}\right)$ goodness of fit test was used, table 8 indicates the cross tabulation between the APS and HBDI.

Table 8. APS * HBDI Scale Cross Tabulation

\begin{tabular}{cccccccc}
\hline & & \multicolumn{5}{c}{ HBDI } & \multirow{2}{*}{ Total } \\
\cline { 3 - 7 } & PERSONALITY & $\mathbf{1}$ & $\mathbf{2}$ & $\mathbf{3}$ & $\mathbf{4}$ & 71 \\
\hline \multirow{2}{*}{ APS } & $\mathbf{1}$ & 49 & 9 & 13 & 0 & 196 \\
& $\mathbf{2}$ & 3 & 169 & 19 & 5 & 158 \\
& $\mathbf{3}$ & 3 & 2 & 149 & 4 & 49 \\
& $\mathbf{4}$ & 1 & 5 & 3 & 40 & 474 \\
\hline
\end{tabular}

Table 9. Represents $\chi 2$ Test for Goodness of Fit between APS and HBDI

\begin{tabular}{lccc}
\hline & Value & df & Sig \\
\hline Pearson Chi-Square & 8.823 & 9 & .000 \\
Likelihood Ratio & 688.003 & 9 & .000 \\
Linear-by-Linear Association & 288.555 & 1 & .000 \\
N of Valid Cases & 474 & & \\
\hline
\end{tabular}

Table 9 indicated that Pearson Chi-Square value $=8.823$ and this value is statistically significant $(\alpha=0.05)$. Table 10 represents Pearson's Correlation between the APS and HBDI scales, it equals 0.78 , and this value is statistically significant $(\alpha=0.05)$.

Table 10. Correlation between APS and HBDI

\begin{tabular}{lcccccc}
\hline & & \multicolumn{2}{c}{$\begin{array}{c}\text { Asymp. Std. } \\
\text { Error }\end{array}$} & Approx. T & Approx. Sig. \\
\hline Interval by Interval & Pearson's R & .781 & .032 & 27.174 & .000 \\
Ordinal by Ordinal & Spearman Correlation & .782 & .031 & 27.228 & .000 \\
\hline
\end{tabular}

\subsection{Results of Question 4}

For answering Q4 which states: "What is the relationship between Physiognomy scale and APS?" Chi square $\left(\chi^{2}\right)$ goodness of fit test was used, table 11 indicates Pearson's Correlation between APS and Physiognomy, it equals 1, and this value is statistically significant $(\alpha=0.05)$. 
Table 10. Correlation between APS and Physiognomy

\begin{tabular}{lccc}
\hline & & Value & Sig. \\
\hline Interval by Interval & Pearson's R & 1.00 & .000 \\
Ordinal by Ordinal & Spearman Correlation & 1.00 & .000 \\
\hline
\end{tabular}

\section{Discussion}

The results indicated that physiognomy is a useful method to predict the individual personality. This conclusion was based upon the high positive correlation between physiognomy scales and HBDI. HBDI is a well-known international scale. Thousands of studies were conducted using this scale. It has been translated into different languages, and its psychometric characteristics were approved in several countries. The results of the study were similar to the findings of Hassin and Trope (2000), Kini and Kumar (2014), Caulfield, Ewing, Bank and Rhodes (2016), Awaja (2017) Zhang, Qin, Lei Dong, Gao, Xu, Hu (2017). The results proved that APS scale is a reliable scale. It is easy to apply, provides fast results, offers better accurate prediction of personality and creates absolute confidence in judgments. The high correlation between determining personality using facial features and the physiognomy using different body features (APS) indicates that physiognomists were well trained and highly experienced persons. The results showed that APS is a valid scale for predicting personalities.

\section{Recommendations}

According to the results, the researchers recommend the following:

1- Psychologists and decision makers who work in human resources are recommended to use physiognomy scale for predicting the individuals' personalities in order to better understand them.

2- Furthermore, research can usefully examine the roles that physiognomy played in the social relationships, the relationship between personality types and human psychological and body health.

3- Furthermore, research is needed to extract psychometric characteristics of APS in other cultures and countries.

\section{Conclusion}

Personality is an important topic that has occupied researchers and practitioners in the field of psychology and mental health, as it affects the individuals' interaction with themselves and with others. This study has demonstrated how physiognomy was perceived as a signifier in determining the personality type using body features.

The study demonstrated that it is possible to judge a personality quickly and easily and with significant accuracy through a person's body features depending on physiognomy principles. This has been confirmed through the comparison between the HDBI and the physiognomy scale which was designed for this purpose.

\section{Acknowledgements}

The researchers would also like to show their gratitude to the main team for their efforts in data entry, typing, and instruments application ( $\mathrm{Ph} \_$Saher Abdel Raouf Elsherif; Dr_Jumana Essa Majdalawi; Mrs Maysaa Aljebreini; Yasmine" Moh'd Fahmi" Farrah; Safa'a Hamdo Tabbal; Diana Mohammad Alkhalaileh; Mrs Suhair Saleh Mazher; Lulua Hashim AL-Mohammedi; Emad Mohamed Ali Ayad; Mrs Ghada Shaher Abu Shaout; Mohammad Salah AL-Qudah; Mrs Rola A adawi; Dr Amani basheer albiss; Dr Sona Omar Abbadi; Mrs Khaled Abu Bakir; Eng Baker Shareef), and the support team for their efforts in instruments application ( Osama Ziad Omar Abu Sneneh; Wala'a Abu Ajameiah; Noura Almariri; Shatha Mohammed Al-Omari; Hanan Shammot; Khalid Alnajjar; Jumana Jebrin muzher; Salwa Alhadid; Abdalmonem Khalel Faraj; Nasha'at Ghanaiem; All Members Of Alfaraseh; Club Group On Facebook; Youth for development ).

\section{Funding}

No funding was received for this work. 


\section{Competing interests}

The authors declare that they have no competing interests.

\section{References}

Abdulkhaliq, A. (1996). Measuring personality. The Committee of authorship, translation and publication World Publishing Council.

Alhelat, M. (2015). Herman Scale of Thinking Patterns. Amman: Debono Center for Teaching Thinking.

Angler, B. (2009). Personality Theories. Belmont, CA: Wadsworth, Cenage Learning.

Awaja, K. (2017). Human Personality Derivation Using Ontology-Based Modern Physiognomy. Master thesis. Islamic University. Gaza.

Bahij, A. (2010). Reading People Remotely, Cairo: Dar Alhilal for Publication and Distribution.

Benjamin Jr, L. T. (2007). A brief history of modern psychology. Blackwell Publishing.

Caulfield, F., Ewing, L. Bank, S., \& Rhodes, G. (2016). Judging trustworthiness from faces: Emotion cues modulate trustworthiness judgments in young children. British Journal of Psychology, 107, 503-518.

Encyclopedia Britannica. Physiognomy. Retrieved from https:/www.britannica.com/topic/physiognomy-divination. Retrieved on 2/march/2018.

Gavrilescu, M., \& Vizireanu, N. (2017). Predicting the Sixteen Personality Factors (16PF) of an individual by analyzing facial features. Journal on Image and Video Processing, 59, 1-19. https://doi.org/10.1186/s13640-017-0211-4

Gubari, T., \& Abu Shaiera, K. (2010). Personality Psychology. Amman: Al- Mojtama Alarabi Library.

Hassin, R., \& Trope. Y. (2000). Facing Faces: Studies on the Cognitive Aspects of Physiognomy. Journal of Personality and Social Psychology, 78(5), 837-852. https://doi.org/10.1037/0022-3514.78.5.837

Hdeeb, K. (1998). The book of Face Physiognomy science. Cairo: Dar Alfkr Alarabi. Retrieved from http://www.amazingfacereading.com/history

Ilm al Kaff (without date). Retrieved from http://www.johnnyfincham.com/history/arabic.htm

Isawi, A. (2002). Personality Psychology. Alexandria: Manshat Al- Maaref.

Jalal, Ibrahim. (2011). The Book of Physiognomy. Bierut: Dar Mashark Publishing.

Jeel, F. (2000). Mental Health and Personality Psychology. Alexandria: Almaktabah Aljamieh.

Kini, P., \& Kumar, R. Personality Identification using Facial Features. The International Journal of Engineering and Science, 3(12), 39-47.

Lelić, E. (2017). Physiognomy ('ilm-i firāsat) and Ottoman Statecraft: Discerning Morality and Justice. Arabica, 64(3-4), 609-646.

Mac Fulfer, J.D. (1996). Amazing Face Reading. New York: Good Press.

Mar, T. T. (1974). Face reading: the Chinese art of physiognomy: Dodd, Mead. Retrieved from https://askastrologer.com/Physiognomy.html Face reading techniques

$\begin{array}{lllll}\text { Merriam Webster dictionary. } & \text { Retrieved } & \text { from }\end{array}$ https://www.merriam-webster.com/dictionary/physiognomy.

Mustafa, F. (2011). Introduction to Behavior and Emotional Disorders. Amman: Dar Almasira.

Nofal, M., \& Abu Awad, F. (2007). Hermann's Brain Dominance Instrument Psychometric Characteristics and its Use to Reveal Patterns of Brain Dominance. Jordan Journal of Educational Sciences, 3(2), 433-471.

Oxford Dictionary. Physiognomy. Retrieved $2 / \mathrm{march} / 2018$ from https://en.oxforddictionaries.com/definition/physiognomy

Parsons, J. (1747). Human Physiognomy Explain'd in the Crounian Lectures on Muscular Motion for the Year. Philosophical Transactions (16831775).

Relationship Between Body Types and Character. Retrieved 2/march/2018 From 
http://facereadingdictionary.com/relationship-between-body-types-and-character/face-reading-physiognomy-me aning/

Roy Porter. (2003). Marginalized Practices. The Cambridge History of Science: Eighteenth-century science. Cambridge: Cambridge University Press.

Salhi, S. (2013). The Effect of Personality Traits and Psychological Adaptation upon Academic Achievement among University Students. Ph.D Dissertation. Algeria.

Sutin, A., \& Terracciano, A. (2016). Five-Factor Model Personality Traits and the Objective and Subjective Experience of Body Weight. Journal of Personality, 84(1), 102-113. https://doi.org/10.1111/jopy.12143

Zhang, T., Qin, R., Dong, Q., Gao, W., Xu, H., \& Hu. Z. (2017). Physiognomy: Personality traits prediction by learning. International Journal of Automation and Computing, 14(4), 386-395. https://doi.org/10.1007/s11633-017-1085-8

\section{Appendix A}

Name:

Mobile:

After answering questions on the following 56 items calculate the yes items (only) for each personality type

\begin{tabular}{|l|l|}
\hline A & \\
\hline B & \\
\hline C & \\
\hline D & \\
\hline
\end{tabular}




\begin{tabular}{|c|c|c|c|c|}
\hline \multicolumn{5}{|c|}{ HBDI } \\
\hline No. & $\begin{array}{l}\text { Personality } \\
\text { Type }\end{array}$ & Item & Yes & No \\
\hline 1 & A & My meticulousness and accuracy may make me look without emotions. & & \\
\hline 2 & $\mathrm{C}$ & I work with others for a common purpose (for fun). & & \\
\hline 3 & A & $\begin{array}{l}\text { I realize the numbers and I understand their implications and I have the ability to calculate them and adapt them to my } \\
\text { personal interests }\end{array}$ & & \\
\hline 4 & $\mathrm{C}$ & I have the ability to anticipate the needs of others and then take them into account & & \\
\hline 5 & $\mathrm{D}$ & Without deep thought I realized a lot of things with intuition and friendliness & & \\
\hline 6 & $\mathrm{~B}$ & Be careful and anxious and care about the consequences so much for fear of losing & & \\
\hline 7 & $\mathrm{C}$ & The most beautiful moments are the moments that I am happy and the happiest of others & & \\
\hline 8 & $\mathrm{D}$ & I am passionate about the new goals and devote my time and effort to it all & & \\
\hline 9 & A & I can determine the cause of the problem when it occurs and then suggest the appropriate solution & & \\
\hline 10 & $\mathrm{~B}$ & I cannot tolerate chaos; on the contrary I arrange and organize all private and public things in my work. & & \\
\hline 11 & $\mathrm{C}$ & I have the desire and the potential to develop, maintain and communicate with others & & \\
\hline 12 & $\mathrm{D}$ & I have money to spend and it is difficult to collect & & \\
\hline 13 & $\mathrm{~A}$ & I am not a Stingy, but I spend money after a logical analysis and Careful considerations & & \\
\hline 14 & $\mathrm{D}$ & Routine and restricted work bothers me and I always like change. & & \\
\hline 15 & $\mathrm{~B}$ & I keep my things and property in my own way & & \\
\hline 16 & $\mathrm{D}$ & Some people says that I am impulsive and my actions cannot be expected. & & \\
\hline 17 & A & People describe me as being rational & & \\
\hline 18 & A & I feel comfortable when I achieved my planned goal & & \\
\hline 19 & $\mathrm{~B}$ & I do things in a sequential way and have accuracy in my work & & \\
\hline 20 & $\mathrm{C}$ & I consider that my good relationship with others is the most precious thing I have & & \\
\hline 21 & $\mathrm{~B}$ & I tend to do more direct actions more than depending upon reflections, thinking and theory. & & \\
\hline 22 & $\mathrm{C}$ & I enjoy serving and helping others whenever they need it & & \\
\hline 23 & A & I find myself thinking and I am drawn away from passion and feelings & & \\
\hline 24 & $\mathrm{~B}$ & I depend on others for achieving my goals & & \\
\hline 25 & $\mathrm{C}$ & I enjoy talking to others about my feelings and my own stories & & \\
\hline 26 & $\mathrm{D}$ & I am tempted by unusual ideas that others call crazy ideas & & \\
\hline 27 & A & I have a great ability to explain events and to deduce their precise events & & \\
\hline 28 & $\mathrm{~B}$ & I have the ability to continue working until it's done & & \\
\hline 29 & $\mathrm{C}$ & I feel good in the enthusiasm of others & & \\
\hline 30 & A & I have a unique knowledge of scientific and technological subjects & & \\
\hline 31 & $\mathrm{C}$ & I consider myself compassionate, kind and help others whenever they need & & \\
\hline 32 & $\mathrm{D}$ & I like to work in more than one thing at a time & & \\
\hline 33 & $\mathrm{C}$ & I often watch the faces of others when they talk to me & & \\
\hline 34 & $\mathrm{D}$ & I often have new ideas & & \\
\hline 35 & $\mathrm{~B}$ & I do not like to be interrupted during my routines work & & \\
\hline 36 & $\mathrm{~B}$ & I feel comfortable giving directions for classification, arrangement and organization & & \\
\hline 37 & $\mathrm{D}$ & I usually care about the general picture and do not look into the details & & \\
\hline 38 & A & I think work is far more important than human feelings & & \\
\hline 39 & A & Others prefer me as an administrative leadership & & \\
\hline 40 & $\mathrm{~B}$ & I make my commitments and make sure to do them & & \\
\hline 41 & $\mathrm{~B}$ & People describe me as being careful & & \\
\hline 42 & $\mathrm{D}$ & I enjoy the spontaneous sense of humor that might cause problems to me. & & \\
\hline 43 & $\mathrm{~B}$ & It is best to know the instructions in a specific and clear manner to leave the order without instructions & & \\
\hline 44 & $\mathrm{D}$ & People describe me as an adventurer & & \\
\hline 45 & $\mathrm{~B}$ & At work I like to know the details and steps I will be doing & & \\
\hline 46 & $\mathrm{D}$ & I do not like the rules and I feel that they are restricting me & & \\
\hline 47 & $\mathrm{C}$ & People describe me as emotional & & \\
\hline 48 & $\mathrm{C}$ & I love communicating with others (or) hearing poetry (or) fairy tales & & \\
\hline 49 & A & I feel that laws and sanctions must be implemented firmly and without emotion or courtesy & & \\
\hline 50 & A & I like to stay away from things that are not guaranteed or whose results can not be expected & & \\
\hline 51 & $\mathrm{C}$ & I love helping others and giving them my time, money and effort & & \\
\hline 52 & $\mathrm{~B}$ & I like short planning of any work I will do & & \\
\hline 53 & $\mathrm{D}$ & When I buy a new device, I try to operate it myself without resorting to the operating manual & & \\
\hline 54 & $\mathrm{C}$ & I like listening to the problems of others and emotionally support them & & \\
\hline 55 & $\mathrm{D}$ & I tend to judge things on my own intuition and my expectations more than analyzing them. & & \\
\hline 56 & A & I have the ability to handle numbers (or) calculations & & \\
\hline
\end{tabular}




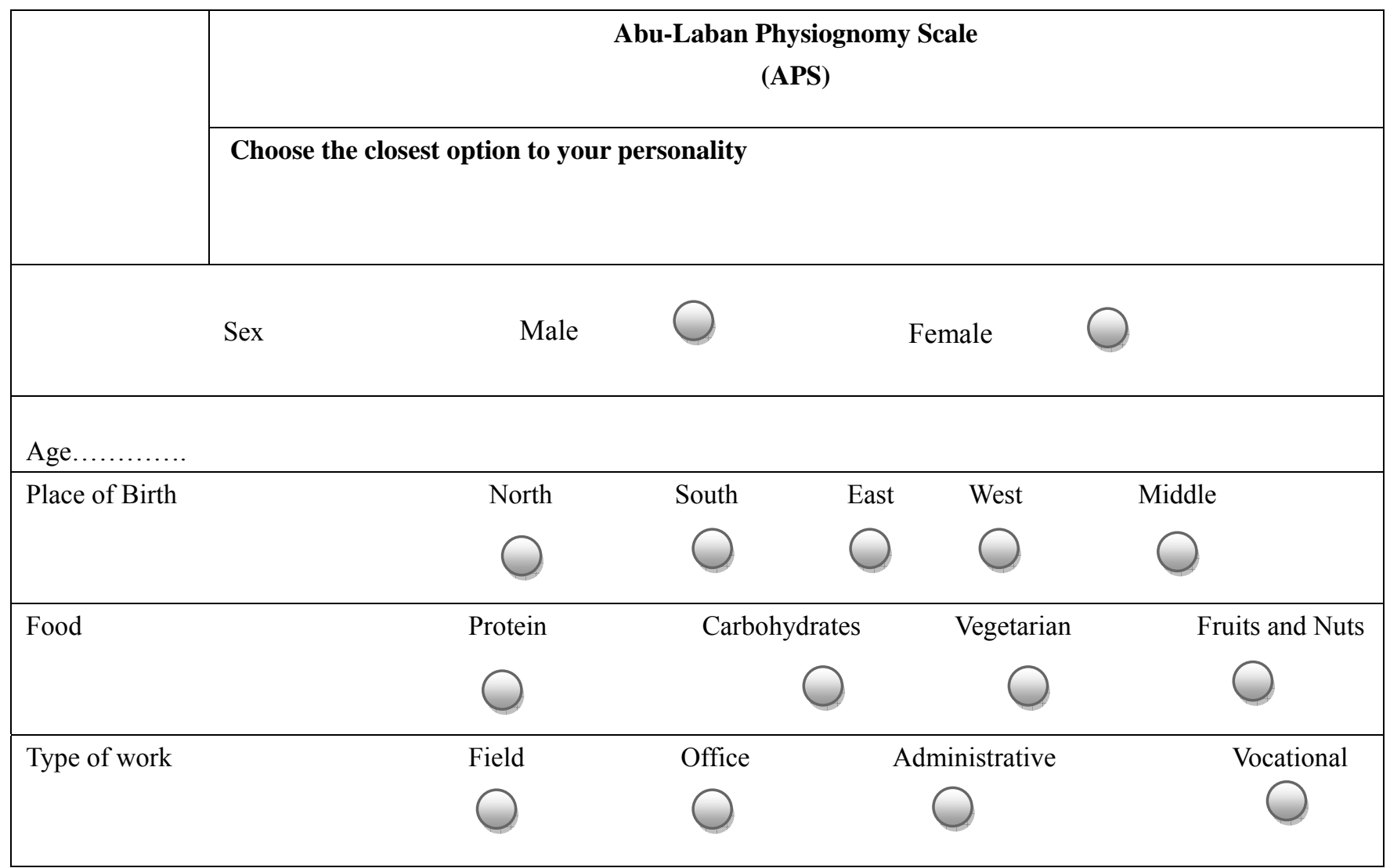




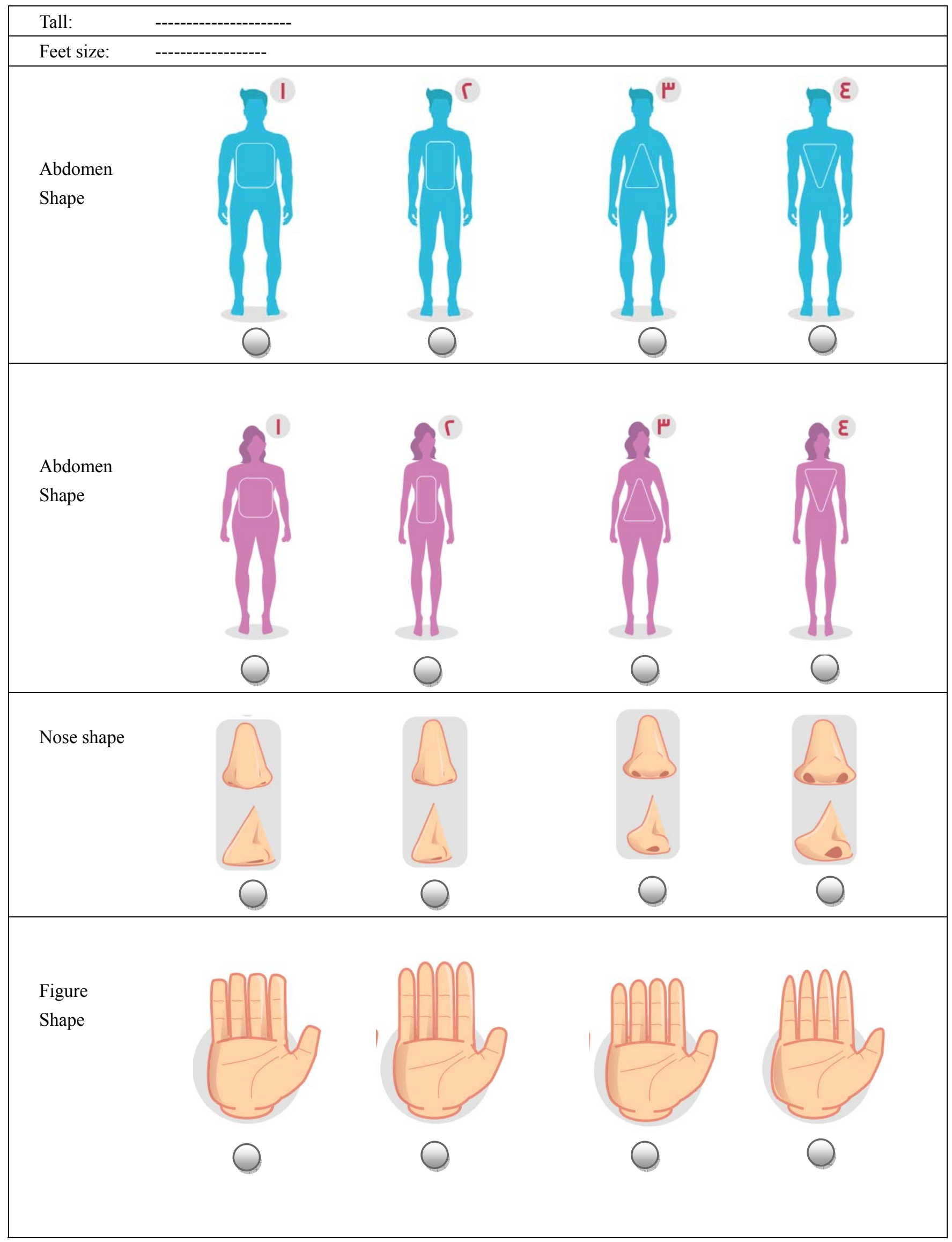




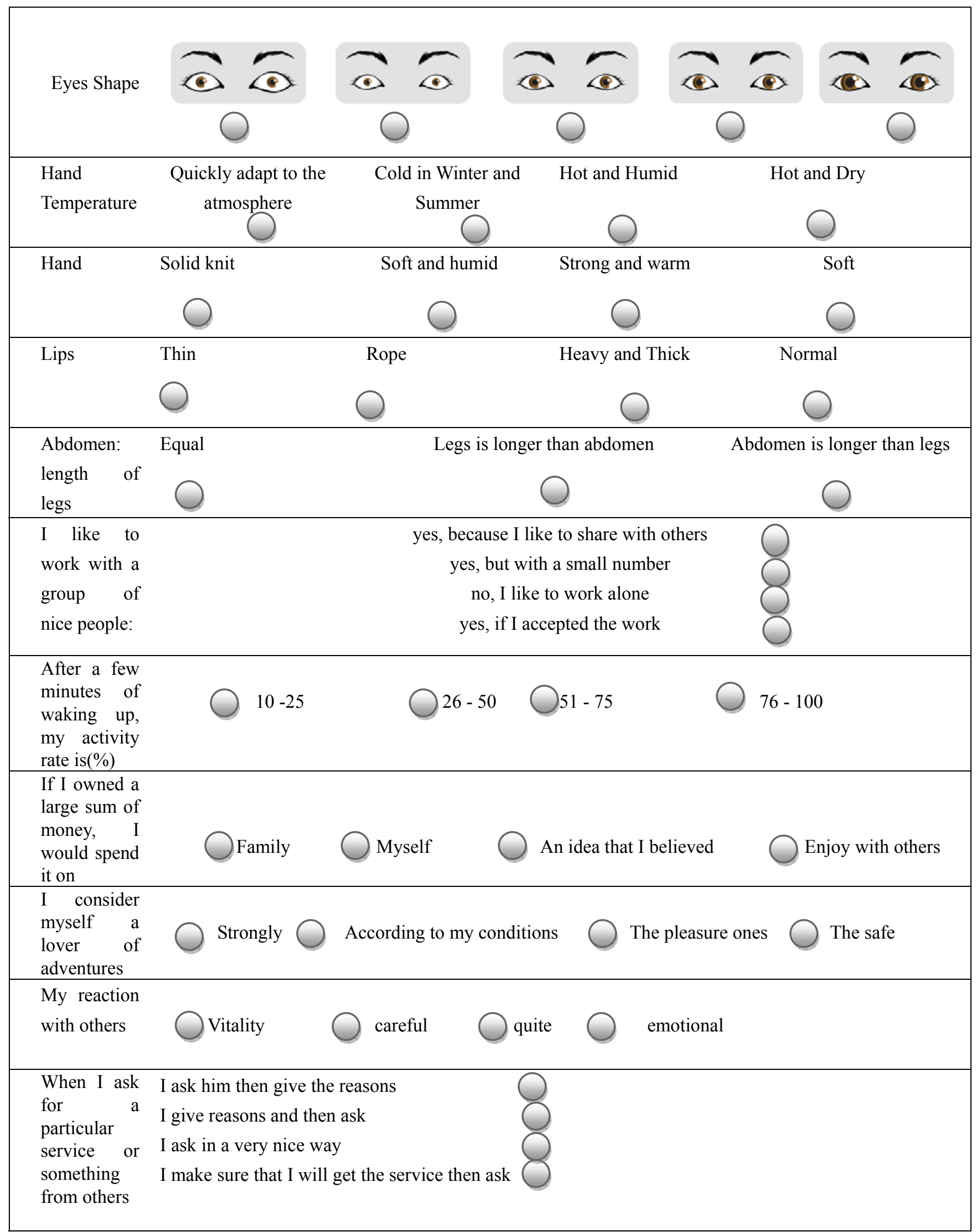

